\title{
Efficacy and Safety of Percutaneous Nephrolithotomy: A Single-center Initial Experience
}

\author{
Ivica Stojanoski ${ }^{1 *}$, Toni Krstev ${ }^{1}$, Lazar lievski ${ }^{1}$, Nerhim Tufekgioski ${ }^{1}$, Sotir Stavridis ${ }^{2}$ \\ ${ }^{1}$ Department of Urology, General Hospital "8 ${ }^{\text {th }}$ September", Skopje, Republic of Macedonia; ' 2 niversity Clinic of Urology, Skopje, \\ Republic of Macedonia
}

Edited by: Ksenija Bogoeva-Kostovsk Citation: Stojanos Stavridis S. Efficacy and Safety of Percutaneous Nephrolithotomy: A Single-center Initial Experience. Open Access Maced J Med Sci. 2020 Aug 30; 8(B):838-844
https://doi.org/10.3889/oamjms.2020.525 eywords: Percutaneous nephrolithotomy; Renal stones; Urolithiasis; Lithotripsy; Safety "Correspondence: Ivica Stojanoski, Department

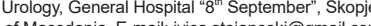
Republic of Macedonia. E-mail: ivica.stojanoski@gmail.com Revised: 26-May-2020 Accepted: 06-Jun-2020 Copyright: ๑ 2020 lvica Stojanoski, Toni Krstev, Sotir Stavridis Funding: This research did not receive any financial Competing Interests: The authors have declar competing interests exis Open Access: This is an open-access article distributed under the terms of the Creative Commons Attribution(

\begin{abstract}
BACKGROUND: In the age of modern medicine, thanks to the development of small-caliber nephroscope as well as various types of intracorporeal lithotripters, treatment options for renal stones have changed dramatically, and the area of percutaneous nephrolithotomy (PCNL) has expanded. Nowadays, PCNL is not only the first choice in the treatment of stones $>2 \mathrm{~cm}$, as well as complicated renal stones (staghorn stones, multiple stones, and stones associated with abnormal renal anatomy), but is also the method of optimal treatment for medium-sized stones not treated with other less invasive methods.
\end{abstract}

AIM: The purpose of this study is to assess the efficacy and safety of PCNL as monotherapy in the treatment of renal stones larger than $15 \mathrm{~mm}$.

MATERIALS AND METHODS: This study presents a retrospectively prospective study of 14 (4 retrospective and 10 prospective) consecutive patients with renal stones larger than $15 \mathrm{~mm}$ treated with PCNL in the period from January 2020 to March 2020 at the GH "8 September" - Skopje. Pre-operative preparation of patients included: A history along with physical examination, a complete blood count and radiological examinations to assess the size of the stones, the anatomical features of the kidney and its function, and to accurately plan the operative approach. PCNL was performed in the prone-position; lithotripsy was performed with a double, pneumatic and ultrasonic intracorporeal lithotripter Swiss LithoClast Master with the use of the Karl Storz 24-26 fr nephroscope. Postoperatively, patients were monitored on the $1^{\text {st }}, 7^{\text {th }}$, and $30^{\text {th }}$ post-operative day, determining the demographic and clinical characteristics, the efficacy of PCNL, perioperative blood loss, the duration of the operative procedure, the duration of hospital stay, and the resulting intraoperative and post-operative complications.

RESULTS: The study included eight men $(57.1 \%)$ and six women (42.8\%). The mean age of the patients was $52.35 \pm$ 11.00. In $5(35.71 \%)$ patients, the stones were localized in the left kidney, and in $9(64.28 \%)$ patients in the right kidney. The average body mass index was $25.11 \pm 3.92 \mathrm{~kg} / \mathrm{m}^{2}$. The average area of the stones was $371.24 \pm 131.86 \mathrm{~mm}^{2}$. Eleven $(78.57 \%)$ patients had simplex stones, while $3(21.42 \%)$ had complex stones (staghorn stones and multiple stones). The stones were localized in the renal pelvis, upper, middle, and lower calyx at $5(35.71 \%), 2(14.28 \%), 4$ $(28.57 \%)$, and $3(21.42 \%)$ patients, respectively. The mean value of pre- and post-operative serum hemoglobin was $13.94 \pm 1.00 \mathrm{~g} / \mathrm{dl}$ and $11.77 \pm 1.51 \mathrm{~g} / \mathrm{dl}$, respectively. The effectiveness of the procedure on the $1^{\text {st }}$ post-operative day assessed by ultrasound diagnostics and kidney-ureter-bladder X-ray was $78.57 \%$. The success rate on the $30^{\text {th }}$ postoperative day after additional procedures was $92.85 \%$. The average operating time in the entire series was 119.28 $\pm 9.42 \mathrm{~min}$. The average hospital stay was $5.57 \pm 1.11$ days. The average operative blood loss was $2.19 \pm 0.88 \mathrm{~g} / \mathrm{dl}$.

CONCLUSION: The results of this retrospectively prospective study confirm that PCNL is a minimally invasive, safe and effective method for removing renal stones. This method, with the development of new technologies, has an increasingly important role in the modern surgical treatment of nephrolithiasis. PCNL can also be performed in the early stages of the learning curve without compromising patient safety and treatment benefits. The procedure is safe and effective, performed even by less experienced urologists if the protocols established for this procedure are followed. This can achieve a rate of success comparable to most established standards without causing major complications.

\section{Introduction}

In the age of modern medicine, urolithiasis continues to be one of the major diseases in the daily practice of urologists. Due to the low morbidity and excellent fragmentation of the stones, extracorporeal shock wave lithotripsy (ESWL) has long been recommended as the first line of treatment for most patients with stone disease. However, thanks to the development of small-caliber nephroscope, as well as various types of intracorporeal lithotripters, nephroscopy has become a much less invasive and easily feasible method with a small number of complications. This significant improvement in urological armamentarium has led to endourological techniques being more attractive and effective in the treatment of nephrolithiasis [1], [2].

Percutaneous nephrolithotomy (PCNL) since its initial introduction in 1976 by Fernstrom and Johansson, has been widely used in the treatment of large renal stones and remains the gold standard for the treatment of complicated renal stones (staghorn stones, multiple stones, stones associated with abnormal renal anatomy, 
and stones that are not treated with other less invasive methods) [3]. However, although PCNL is considered a minimally invasive procedure, it is still a surgical technique that can be associated with critical complications such as bleeding and septicemia, which has led to many efforts to reduce morbidity and increase the effectiveness and efficacy of PCNL because PCNL remains the first treatment line indicated for many cases [4], [5].

In this combined retrospectively prospective study, we present our initial experiences in the implementation of PCNL in our institution.

\section{Objective}

The purpose of this study is to assess the efficacy and safety of PCNL as monotherapy in the treatment of renal stones larger than $15 \mathrm{~mm}$ by determining the stone-free rate - SFR, the need for additional procedures, the degree of complications after treatment, the degree of blood loss, the duration of the procedure, and the duration of hospital stay.

\section{Materials and Methods}

We performed a retrospectively prospective study in 14 (4 retrospective and 10 prospective) consecutive patients with renal stones larger than 15 $\mathrm{mm}$ treated with PCNL in the period from January 2020 to March 2020 at the GH "8 September" - Skopje.

Pre-operative preparation of patients included: Medical history, complete blood count (hemoglobin, serum urea, creatinine, sodium, potassium, uric acid, albumin, protein, PTH, and Vitamin D3), urine sediment, tests for hemostasis and blood group, urine culture, electrocardiogram (12 drains), RTG of the heart and lungs, and consultation with an anesthesiologist. The degree of anesthesia risk was determined by the scale of the American Society of Anesthesiologists (ASA) [6].

Exclusion criteria were age of a patient under 18 years and over 80 years, stones $<15 \mathrm{~mm}$, ASA index above III, presence of cardiovascular or pulmonary insufficiency, renal insufficiency, untreated urinary tract infection, renal abscess, congenital anomalies, including obstruction of the ureteropelvic junction or ureterovesical junction, presence of uncorrected coagulopathies, bilateral upper urinary tract obstruction, pregnant women, and radiolucent stones.

Before each intervention, an ultrasonographic examination of the ultrasonography (UT) and computerized tomography urography was performed to assess the size of the stones, the anatomical features of the kidney and its function, and to accurately plan the operative approach. The size of the stone was calculated based on the widest diameter of the CT urography series, and Hounsfield unit (HU) was measured for radiographic assessment of the stone density. The surface of the stones was determined by the formula by Tiselius and Anderson: The surface of the stones $=$ length $\times$ width $\times 3.14 \times 0.25$.

With patients taking acetylsalicylic acid or other anticoagulants, they were discontinued for 5-7 days before treatment. All patients undertook bowel preparation with macrogol $3350 / 80 \mathrm{mg}$ simethicone the day before treatment according to the manufacturer's protocol and were advised to discontinue the intake of any food the night before treatment. Patients with a bacterial infection detected by urine culture were treated with antibiotic therapy and operated on after receiving a sterile urine culture.

\section{PCNL}

Antibiotic prophylaxis with Amp. ceftriaxone $2 \mathrm{~g}$ was prescribed preoperatively in all patients, as well as thromboembolic prophylaxis with low molecular weight heparin. The procedure began in the position of dorsal lithotomy before the main lithotripsy procedure, with a retrograde application of an open 5-6 Fr ureteral catheter that allowed the injection of contrast material to opacify and distend the collection system and perform artificial hydronephrosis. It was fixed for 18 Fr Foley catheter. Next, the patient was repositioned and placed in a prone position on the operating table compatible with the $\mathrm{C}$-arm. The radiation source was placed under the patient to minimize radiation exposure to the surgeon and medical staff.

After opacification of the collection system by injection of contrast material through the ureteral catheter, puncture of the pyelocaliceal system was performed using an 18 gauge puncture needle under fluoroscopic control. The most common puncture site was the lower calyx. The position at the top of the needle was checked by rotating the "C-arm" to $0^{\circ}$ and $30^{\circ}$. When it was established that the needle was in the calyx, the stylet was removed, and the exact position of the needle was confirmed by urine and contrast aspiration. Next through the puncture needle was placed $0.035 "$ working guidewire. The guidewire was placed under fluoroscopic control. Once the guidewire was well-positioned, the puncture needle was removed, and a $1 \mathrm{~cm}$ incision was made at the site of the wire. Next, the tract was extended through a guidewire with metal telescopic Alken dilators to 24-Fr. Through the last dilator, we introduced the working shirt of the endoscope (with a diameter of $26 \mathrm{Ch}$ ) and through it, we placed the nephroscope. In cases of complicated stones or difficulty in maintaining the percutaneous pathway, we used a second, safety guidewire as an adjunct to the initial working wire. Its purpose was to maintain access to the kidney if the working wire was bent or displaced. This safety wire was stored until the end of the whole surgical procedure. After placing the nephroscope, the 
lithotripsy was performed with a dual, pneumatic and ultrasonic intracorporeal lithotripter, Swiss LithoClast Master, using the KarlStorz 24-26 fr nephroscope. During pneumatic lithotripsy, we used a pressure of $3 \mathrm{~atm}$ and a frequency of $12 \mathrm{~Hz}$, and during ultrasonic lithotripsy, we used a maximum level of sessions of $60-100 \%$. The ultrasound probe was placed through the nephroscope, and the pneumatic probe passed through it. After lithotripsy, we placed nephrostomy (Malecot 18-20 fr) and made a compression bandage. In the presence of nephrostomy tube hemorrhage, it was clamped for $1 \mathrm{~h}$. We removed nephrostomy tube 24-48 $\mathrm{h}$ after the operative treatment depending on the color of the contents in the drainage bag, and the ureteral probe and the Foley catheter, 48-72 $\mathrm{h}$ after treatment.

Postoperatively, the patients were monitored according to the following protocol:

- $\quad 1^{\text {st }}$ post-operative day: Complete blood count, urinary tract UT, and Kidney-Ureter-Bladder (KUB) X-ray

- $\quad$ After 7 days and 1 month: Urinary tract UT and KUB X-ray.

We defined the success of the treatment by determining the success rate - SR, the need for additional procedures, the degree of complications after treatment, the degree of blood loss by determining the difference between pre-operative and post-operative values of hemoglobin and hematocrit, and the duration of the procedure and time.

The effectiveness of the method was assessed by determining the absence of residual fragments from the stones or the presence of clinically insignificant fragments $<4 \mathrm{~mm}$ on the control KUB X-ray examinations on the $1^{\text {st }}$ and $30^{\text {th }}$ post-operative day. The time of the operation was measured from the time of cystoscopic examination and placement of the ureteral probe to the end of the operation and the nephrostomy tube placement. The safety of the method was determined in terms of frequency and severity of intra and post-operative complications. The criterion for post-operative febrility was the increase in body temperature BT $>38.5$ in the postoperative period without the presence of diagnostic criteria for sepsis. Intraoperative and post-operative complications were classified based on the modified Clavien-Dindo scale. Residual stones $>4 \mathrm{~mm}$ were treated with ESWL and ureteral stones migrated to the lower urinary tract by ureterorenoscopy. The hospital stay was calculated from the day of the operation until the day of discharge.

\section{Statistical analysis}

The statistical analysis was performed with SPSS v.19.0 (SPSS Corporation, USA). Fisher's exact test and Chi-square test were used to compare categorical variables and Student's t-test to compare metric variables. The value of $p<0.05$ was considered statistically significant.

\section{Results}

The presented results refer to the demographic and clinical characteristics, PCNL efficacy, perioperative blood loss, duration of the operative procedure, duration of hospital stay and intraoperative and postoperative complications, the chemical composition of stones, and radiographic assessment of the density of the stones by HU. Percutaneous nephrolithotripsy was performed in all patients without overstressing the need for conversion to open surgery.

The pre-operative characteristics of patients, the basic clinical parameters, and stone characteristics are presented in Tables 1 and 2 .

Table 1: Pre-operative characteristics of patients

\begin{tabular}{|c|c|}
\hline Mean age (years \pm SD) & $52.35 \pm 11.00$ \\
\hline \multicolumn{2}{|l|}{ Gender (n/\%) } \\
\hline Male & $8(57.1)$ \\
\hline Female & $6(42.8)$ \\
\hline \multicolumn{2}{|l|}{ Side $(n / \%)$} \\
\hline Right kidney & $5(35.71)$ \\
\hline Left kidney & $9(64.28)$ \\
\hline \multicolumn{2}{|l|}{ Solitary kidney (n/\%) } \\
\hline Contralateral nephrectomy & $1(7.14)$ \\
\hline Contralateral kidney dysfunction & 0 \\
\hline Mean $\mathrm{BMI}\left(\mathrm{kg} / \mathrm{m}^{2} \pm \mathrm{SD}\right)$ & $25.11 \pm 3.92$ \\
\hline \multicolumn{2}{|l|}{ Previous procedures $(\mathrm{n} / \%)$} \\
\hline Pyelolithotomy & $1(7.14)$ \\
\hline ESWL & $4(28.57)$ \\
\hline DJ & $3(21.42)$ \\
\hline Mean length of stones $(\mathrm{mm} \pm \mathrm{SD})$ & $25.28 \pm 5.58$ \\
\hline Mean width of stones $(\mathrm{mm} \pm \mathrm{SD})$ & $18.21 \pm 2.80$ \\
\hline Mean surface area of stones $\left(\mathrm{mm}^{2} \pm \mathrm{SD}\right)$ & $371.24 \pm 131.86$ \\
\hline Mean pre-operative serum creatinine $(\mathrm{mmol} / \mathrm{I} \pm \mathrm{SD})$ & $91.2 \pm 15.98$ \\
\hline Pre-operative serum $\mathrm{Hg}(\mathrm{g} / \mathrm{dl} \pm \mathrm{SD})$ & $13.94 \pm 1.00$ \\
\hline Pre-operative serum HCT $(\% \pm \mathrm{SD})$ & $42.49 \pm 2.52$ \\
\hline \multicolumn{2}{|l|}{ Pre-operative anesthetic risk by ASA ( $n / \%)$} \\
\hline ASA class 1 & $3(21.42)$ \\
\hline ASA class 2 & $9(64.28)$ \\
\hline ASA class 3 & $2(14.28)$ \\
\hline \multicolumn{2}{|l|}{ Features of stones $(\mathrm{n} / \%)$} \\
\hline Solitary stone & $11(78.57)$ \\
\hline Multiple stones & $1(7.14)$ \\
\hline Staghorn stone & $2(14.28)$ \\
\hline \multicolumn{2}{|l|}{ Localization of the stones ( $\mathrm{n} / \%)$} \\
\hline Renal pelvis & $5(35.71)$ \\
\hline Upper calyces & $2(14.28)$ \\
\hline Middle calyces & $4(28.57)$ \\
\hline Lower calyces & $3(21.42)$ \\
\hline Renal pelvis and lower calyces & 0 \\
\hline Renal pelvis and upper calyces & 0 \\
\hline Recurrent lithiasis (n/\%) & $1(7.14)$ \\
\hline Mean density of stones $(\mathrm{HU} \pm \mathrm{SD}$ ) & $949.78 \pm 207.28$ \\
\hline
\end{tabular}

\begin{tabular}{llll}
\hline Parameters & Pre-operative & Post-operative & p value \\
\hline Serum Hg $(\mathrm{g} / \mathrm{dl} \pm \mathrm{SD})$ & $13.94 \pm 1.00$ & $11.77 \pm 1.51$ & 0.00000124 \\
Serum HCT $(\% \pm \mathrm{SD})$ & $42.49 \pm 2.52$ & $33.83 \pm 4.11$ & 0.00000002 \\
Serum creatinine $(\mathrm{mmol} / \mathrm{I} \pm \mathrm{SD})$ & $91.2 \pm 15.98$ & $86.9 \pm 16.28$ & 0.192 \\
\hline HCT: Hematocrit. & & &
\end{tabular}

Despite the clinically significant difference in pre-operative and post-operative values of hemoglobin and hematocrit, $(p=0.00000124)$ and $(p=0.00000002)$, respectively, blood transfusion was not given to any of the patients because they were hemodynamically stable. 
The effectiveness of the procedure (SFR) on the $1^{\text {st }}$ post-operative day evaluated by ultrasound diagnostics and KUB was $78.57 \%$. Three patients postoperatively had clinically significant fragments $>4 \mathrm{~mm}$. Two patients were additionally treated with ESWL and one patient underwent ureterorenoscopy with lithotripsy due to migration of fragments into the distal ureter. The success rate on the $30^{\mathrm{th}}$ post-operative day, after additional procedures, was $92.85 \%$. The average operating time in the entire series was 119.28 $\pm 9.42 \mathrm{~min}$. The average hospital stay was $5.57 \pm 1.11$ days. The average operative blood loss was $2.19 \pm$ $0.88 \mathrm{~g} / \mathrm{dl}$ (Table 3).

Table 3: Results

\begin{tabular}{ll}
\hline SFR $(\mathrm{n} / \%) 1^{\text {st }}$ post-operative day & $11 / 14(78.57)$ \\
Success rate $(\mathrm{n} / \%) 30^{\text {th }}$ post-operative day & $13 / 14(92.85)$ \\
Mean operative time (min \pm SD) & $119.28 \pm 9.42$ \\
Mean operative blood loss (g/dl \pm SD) & $2.19 \pm 0.88$ \\
Mean hospital stay (days \pm SD) & $5.57 \pm 1.11$ \\
Treatment of residual fragments (n/\%) & \\
ESWL & $2(14.28)$ \\
URS & $1(7.14)$ \\
Rehospitalization & 0 \\
\hline SFR: Stone free rate, SD: Standard deviation, ESWL: Extracorporeal shock wave lithotripsy, \\
URS: Ureteroscopy.
\end{tabular}

The chemical composition of the stones is shown in Table 4.

Table 4: Chemical composition (n/\%)

\begin{tabular}{ll}
\hline Calcium oxalate monohydrate & $6(42.85)$ \\
Calcium oxalate dihydrate & $4(28.57)$ \\
Struvite & $2(14.28)$ \\
Brushite & $1(7.14)$ \\
Cystine & $1(7.14)$ \\
\hline
\end{tabular}

Postoperatively, analgesic therapy was required in the first 2 days after the procedure. We removed the transurethral catheter in the first $24-48 \mathrm{~h}$, and the nephrostomy tube the next day. All operative interventions underwent without intraoperative complications. Post-operative complications included two cases of elevated $\mathrm{BT}>38.5^{\circ} \mathrm{C}$ and one case of more intense hematuria who was treated conservatively with Amp. Transamin (tranexamic acid) $1 \mathrm{~g}$. These three severe complications were classified on the modified Clavien-Dindo scale as Grade I and II (Table 5).

Table 5: Complications

\begin{tabular}{lll}
\hline Type of complications & $\mathrm{n}(\%)$ & The Clavien-Dindo classification \\
\hline Intraoperative & $/$ & $/$ \\
Post-operative & $1(7.14)$ & $\mathrm{II}$ \\
$\quad$ Hematuria & $2(14.28)$ & $\mathrm{I}$ \\
$\quad$ Febrility $>38.5^{\circ} \mathrm{C}$ & $3(21.42)$ & \\
$\begin{array}{l}\text { Treatment of complications } \\
\text { Medical therapy }\end{array}$ & \\
Medical therapy $+\mathrm{JJ}$ stent & & \\
\hline
\end{tabular}

\section{Discussion}

In the age of modern medicine, thanks to the development of small caliber nephroscope as well as various types of intracorporeal lithotripters, treatment options for renal stones have changed dramatically and the indicative area of PCNL has expanded [7], [8]. Today, $\mathrm{PCNL}$ is not only the first choice in the treatment of stones
$>2 \mathrm{~cm}$, as well as complicated renal stones (staghorn stones, multiple stones, and stones associated with abnormal renal anatomy) [9] but is a method for optimal treatment of medium-sized stones that are not treated with other less invasive methods [10].

In the European Association of Urology guidelines, the PCNL is recommended as a method of choice for renal stones larger than $20 \mathrm{~mm}$ while ESWL for renal stones $<10 \mathrm{~mm}$. ESWL, retrograde intrarenal surgery, and percutaneous nephrolithotomy (PCNL) are recommended as methods of choice in the treatment of renal stones between 10 and $20 \mathrm{~mm}$. Which minimally invasive technique will be chosen depends on several factors affecting the treatment of renal stones, which can be grouped into four categories [11].

- $\quad$ Factors related to stones: Localization, size, number, and chemical composition.

- $\quad$ Anatomical factors of the kidney: Obstruction or stasis, hydronephrosis, stenosis of the ureteropelvic junction, calyx diverticula, horseshoe kidney, renal ectopia or fusion, and lower pole stones.

- Clinical factors: Infections, obesity, body deformities, coagulopathies, hypertension, and renal failure.

- Technical factors: Availability of modern treatment instruments, operator experience, patient requirements, physician preferences, method success rate, treatment complications, and cost [12].

Conventionally, in PCNL the patient is in a prone position. Prone position provides a larger area for puncture selection, including a puncture of the upper calyx, wider space for manipulation with the nephroscope and lithotripter, and a lower risk of perirenal visceral injury [13]. However, there are drawbacks to performing PCNL in the traditional prone position such as patient discomfort, relatively long intervention time due to patient repositioning, anesthetic risks including circulatory problems, respiratory difficulties, suboptimal airway control, increased sympathetic activity, and possible lesions of the cervical spine or peripheral nerves [14]

In a study conducted in the United Kingdom by Armitage et al. [15] in 1028 patients, PCNL was performed in the prone position and only in $6 \%$ it was performed in the supine position.

In our study, all procedures were performed in a prone position; percutaneous renal access was performed by a urologist under fluoroscopic control. In $12(85.7 \%)$ patients, renal access was performed through the lower calyx, in $1(7.14 \%)$ patient through the middle calyx and in $1(7.14 \%)$ patient through the upper calyx. The choice of approach depended on the location of the stones.

In a study by El-Assmy et al. [16], it is noted that the results of a renal approach performed by a 
urologist are equal to or better than the renal approach performed by a radiologist. Our findings confirm this, the right approach is a prerequisite for complete success in extracting renal stones with PCNL. The ideal tract is the one that provides the shortest and simplest access to all stones.

Renal access to the upper calyx, which is most commonly performed in the $11^{\text {th }}$ and $12^{\text {th }}$ intercostal spaces, is associated with multiple complications due to the proximity of the upper calyx to the lungs. Therefore, pneumothorax, pleural effusion, and calico-pleural fistulas are more commonly seen with access to the upper calyx, and pulmonary complications have been reported in almost a quarter of patients undergoing intercostal access [17]. Only in one patient in our study was the approach supracostal, with no post-operative complications present.

As with other minimally invasive techniques, PCNL is constantly evolving and advancing. Dilatation of the renal route for establishing intrarenal access is one of the most important steps during PCNL. Since the introduction of the first nephrostomy in 1955, this technique has developed steadily, leading to an improvement in the outcome of percutaneous nephrolithiasis. [18], [19], [20].

In 1994, Stoller et al. [21] examined the effects of the Alken coaxial metal dilators and balloon dilators on blood loss, with no significant differences found between the two methods. A study by Kukreja et al. [22] compared the Amplatz dilators, Alken coaxial metal dilators, and balloon dilators. There was less blood loss with the use of the Amplatz dilators, but without a statistically significant difference between them.

In our series, the Alken metal dilators were used and our results in terms of blood loss and safety did not differ from the results of Stoller and Kukreja's study using metal coaxial dilators.

The average operating time in our study was $119.28 \pm 9.42 \mathrm{~min}$, which is similar to the time reported by Kurtulus et al. (2.2 h) [23]. Gupta et al. [24] reported a mean operating time of 80.2 min. Falahatkar et al. [25] also reported a mean operating time of $67.42 \pm 26.25$ min. In a series of 10 cases of outpatient post-operative patients after PNL, Singh et al. [26] had a mean operating time of $48.4 \mathrm{~min}$. In the study of Shahrour and Andonian [27], the mean operating time was 83.5 min.

The longer operating time in our study can be explained by the fact that our procedures were initial in the implementation of PCNL as a method in our institution and were performed by surgeons with an initial level of experience. Furthermore, we calculated the time interval from the initial placement of the ureteral catheter to the fixation of the nephrostomy tube. It should also be noted that we performed subsequent dilatation when establishing the intrarenal route with metal coaxial dilators.

In our study, the effectiveness of the method was assessed by determining the absence of residual fragments from the stones (SFR), or the presence of clinically insignificant fragments $<4 \mathrm{~mm}$ of control KUB X-ray examinations on the $1^{\text {st }}, 7^{\text {th }}$, and $30^{\text {th }}$ postoperative day.

In the study of Albala et al. [28], the success of the treatment is defined in terms of the absence of residual fragments (SFR), or the presence of clinically insignificant fragments $\leq 3 \mathrm{~mm}$ in diameter relative to the initial size of the stones, at the end of the $3^{\text {rd }}$ month, at which the success rate of $95 \%$ for PCNL was achieved. In the Giusti and Shoma studies, the overall SFR was 95.4 and $92 \%$, respectively [29], [30]. A study by Bayar et al. [31] compared the results of PCNL performed for isolated stones in the renal pelvis, upper and lower group of calyces on the one hand, and complex stones on the other, with success rates of $77 \%$ for isolated and $53 \%$ for complex stones.

In our study, the initial SFR for the $1^{\text {st }}$ postoperative day was $78.57 \%$, while the overall success rate for the $30^{\text {th }}$ post-operative day was $92.85 \%$. This result is consistent with Shoma's result. The lower success rate than the results of Albala et al. and Giusti et al. is probably due to our significantly lesser experience with this method. The treatment of residual fragments depended on the location and their size. URS was performed in one (7.14\%) patient and ESWL in $2(14.28 \%)$ patients with total rates of additional procedures of $3(21.42 \%)$. These results are consistent with the results in the literature.

The overall incidence of complications after PCNL is small. Bleeding is the most significant complication of $\mathrm{PCNL}$, with transfusion rates ranging from $1 \%$ to $10 \%$. Bleeding from an arteriovenous fistula or pseudoaneurysm requires immediate embolization and occurs in less than $0.5 \%$ of patients. Acute hemorrhage is usually venous in nature, and in most cases, the clamping of the placed nephrostomy tube is sufficient to control it. In PCNL, absorption of the irrigation medium may occur, which is why it is necessary to use saline as a means of irrigation. In supracostal puncture, there is a risk of pneumothorax, hemothorax, and pleural effusion, and in $4-12 \%$ of cases, pleural drainage is required. Colon injury is a rare complication, often diagnosed with a post-operative nephrostogram and may be retroperitoneal and intraperitoneal. The most common complications of PCNL are fever, bleeding, and prolonged leakage of urine through the renal approach [32].

In the research of Netto et al. [33] in a series of 119 patients, the complication rate was $28.5 \%$. The most common major complications were bleeding requiring blood transfusion ( $n=25)$, pneumothoraxhydrothorax $(n=2)$, sepsis-bacteremia $(n=2)$, ileus $(n=2)$, and prolonged urine leakage $(n=2)$. In the study of Tefekli et al. [34], the total incidence of complications graded according to the Clavien-Dindo scale with grades $3-5$ was $10.5 \%$, while for grades 1 and 2 , the total complication rate was $20.3 \%$. 
In a Troxel and Low [35] study of 128 patients, $42.4 \%$ of patients had a temperature higher than $38.5^{\circ} \mathrm{C}$, although all patients received pre-operative and post-operative antibiotic prophylaxis.

In our study, none of the cases had a complication of Grade III, IV, or V on the Clavien-Dindo scale. This is due to the fact that this is a group of wellselected cases with moderate-sized kidney stones. Post-operative complications were classified according to the Clavien-Dindo scale, Grade I and II. Prolonged hematuria but without the need for transfusion was observed in $1(7.14 \%)$ patient. (Clavien-Dindo II) while elevated post-operative TT was observed in 2 (14.28) patients. (Clavien-Dindo I) The temperature was higher than $38.5^{\circ} \mathrm{C}$, and it was treated with antibiotics and antipyretics. The overall complication rate was $21.42 \%$, according to the study by Tefekli et al.

No significant intraoperative complications were observed in this study. Intraoperative bleeding occurred in $1(7.14 \%)$ patient. The bleeding was minor and originated in the accessory tract, requiring neither blood transfusion nor embolization. The patient nephrostomy tube (Malecot $24 \mathrm{Fr}$ ) was clamped in a period of $1 \mathrm{~h}$ for tamponade and stopping the hemorrhage.

The smaller rate of complications in our study is probably due to a small group of highly selected patients. The majority of patients had an isolated stone in the renal pelvis with consequent hydronephrosis, and the lower calyx was most commonly punctured.

We used the difference between pre-operative and post-operative hemoglobin levels as an indicator of blood loss, the average reduction in hemoglobin level was $2.19 \mathrm{~g} / \mathrm{dl}$, which was higher than the results of a study by Shaban et al. [36] where the fall in hemoglobin was $0.79 \mathrm{~g} / \mathrm{dl}$. Despite the higher blood loss value in this study, none of the patients in our series received a blood transfusion because the hemoglobin drop was not below $9 \mathrm{~g} / \mathrm{dl}$ and all patients were hemodynamically stable.

In the current study, the mean length of hospital stay was (5.57 \pm 1.11 days). Similar results in terms of hospital stay are shown in the study of Giusti et al. [29], where the mean hospitalization at standard PCNL is 5.3 days. Albala et al. [28] reported an average hospital stay of 2.66 days, while Netto et al. [33] reported 3.1 days.

The small number of patients is the main limiting factor in this study. The study also included the initial PCNL, which is another limiting factor.

\section{Conclusion}

The results of this retrospectively prospective study confirm that PCNL is a minimally invasive, harmless, safe, and effective method for removing renal stones. This method, with the development of new technologies, has an increasingly important role in the modern surgical treatment of nephrolithiasis. PCNL can also be performed in the early stages of the learning curve without compromising patient safety and treatment benefits. The procedure is safe and effective, performed even by less experienced urologists if the protocols established for this procedure are followed. This can achieve a rate of success comparable to most established standards without causing major complications.

\section{References}

1. Turney BW. Trends in urological stone disease. BJU Int. 2011;24:382-6.

2. Rosa M, Usai P, Miano R, Kim FJ, Agrò E, Bove P, et al. Recent finding and new technologies in nephrolithiasis: A review of the recent literature. BMC Urology. 2013;13:10-35. https://doi. org/10.1186/1471-2490-13-10

3. Fernström I, Johansson B. Percutaneous pyelolithotomy. A new extraction technique. Scand J Urol Nephrol. 1976;10(3):257-9. PMid:1006190

4. Gupta NP, Mishra S, SethA,AnandA. Percutaneous nephrolithotomy in abnormal kidneys: Single-center experience. Urology. 2009;73(4):710-4. https://doi.org/10.1016/j.urology.2008.10.070 PMid:19193423

5. Liatsikos EN, Kallidonis P, Stolzenburg JU, Ost M, Keeley F, Traxer $\mathrm{O}$, et al. Percutaneous management of staghorn stones in horseshoe kidneys: A multi-institutional experience. J Endourol. 2010;24(4):531-6. https://doi.org/10.1089/end.2009.0264 PMid:20218888

6. Dobson G, Chong M, Chow L, Flexman A, Kurrek M, Laflamme $C$, et al. Guidelines to the practice of anesthesiarevised edition 2017. Can J Anaesth. 2017;64(1):65-91. https:// doi.org/10.1007/s12630-016-0749-0

PMid:27837405

7. Rassweiler J, Rassweiler MC, Kenngott H, Frede T, Michel MS, Alken $\mathrm{P}$, et al. The past, present and future of minimally invasive therapy in urology: A review and speculative outlook. Minim Invasive Ther Allied Technol. 2013;22(4):200-9. https://doi.org/ 10.3109/13645706.2013.816323

PMid:23808367

8. Resorlu B, Unsal A, Tepeler A, Atis G, Tokatli Z, Oztuna D, et al. Comparison of retrograde intrarenal surgery and minipercutaneous nephrolithotomy in children with moderate-size kidney stones: Results of multi-institutional analysis. Urology. 2012;80(3):519-23. https://doi.org/10.1016/j.urology.2012.04.018 PMid:22673546

9. Akman T, Binbay M, Ozgor F, Ugurlu M, Tekinarslan E, Kezer C, et al. Comparison of percutaneous nephrolithotomy and retrograde flexible nephrolithotripsy for the management of 2-4 $\mathrm{cm}$ stones: A matched pair analysis. BJU Int. 2012;109(9):13849. https://doi.org/10.1111/j.1464-410x.2011.10691.x PMid:22093679

10. Muslumanoglu AY, Tefekli A, Karadag MA, Tok A, Sari E, Berberoglu Y. Impact of percutaneous access point number and location on complication and success rates in percutaneous nephrolithotomy. Urol Int. 2006;77(4):340-6. https://doi. org/10.1159/000096339

PMid:17135785 
11. Türk C, Knoll T, Petrik A, Sarica K, Skolarikos A, Straub M, et al. Guidelines on Urolithiasis. Arnhem, Netherlands: European Association of Urology; 2013. https://doi.org/10.1016/j. eururo.2015.07.041

12. Fuchs GJ, Patel A. Treatment of renal stones. In: Smith AD, Badlani GH, Bagley DH, editors. Smith's Textbook of Endourology. St Louis: Quality Medical Publishing; 1996. p. 590-621.

13. Cracco CM, Scoffone CM, Scarpa RM. New developments in percutaneous techniques for simple and complex branched renal stones. Curr Opin Urol. 2011;21(2):154-60. https://doi. org/10.1097/mou.0b013e3283436d32

\section{PMid:21252683}

14. de la Rosette JJ, Tsakiris P, Ferrandino MN, Elsakka AM, Rioja J, Preminger GM. Beyond prone position in percutaneous nephrolithotomy: A comprehensive review. Eur Urol. 2008;54(6):1262-9. https://doi.org/10.1016/j.eururo.2008.08.012 PMid:18707807

15. Armitage JN, Irving SO, Burgess NA, British Association of Urological Surgeons Section of Endourology. Percutaneous nephrolithotomy in the United Kingdom: Results of a prospective data registry. Eur Urol. 2012;61(6):1188-93. https:// doi.org/10.1016/j.eururo.2012.01.003

PMid:22244778

16. El-Assmy AM, Shokeir AA, Mohsen T, El-Tabey N, El-Nahas AR, Shoma AM, et al. Renal access by urologist or radiologist for percutaneous nephrolithotomy-is it still an issue? J Urol. 2007;178(3):916-20. https://doi.org/10.1016/j.juro.2007.05.015

17. Munver R, Delvecchio FC, Newman GE, Preminger GM. Critical analysis of supracostal access for percutaneous renal surgery. J Urol. 2001;166(4):1242-6. https://doi.org/10.1016/ s0022-5347(05)65745-x

PMid:11547050

18. Falahatkar S, Neiroomand H, Akbarpour M, Emadi SA, Khaki N One-shot versus metal telescopic dilation technique for tract creation in percutaneous nephrolithotomy: Comparison of safety and efficacy. J Endourol. 2009;23(4):615-8. https://doi. org/10.1089/end.2008.0330

PMid:19335153

19. Baldwin D, Maynes LJ, Desai PJ, Jellison FC, Tsai CK, Barker GR. A novel single step percutaneous access sheath: The initial experience. J Urol. 2006;175(1):156-61. https://doi. org/10.1016/s0022-5347(05)00020-0

20. Safak M, Gogus C, Soygur T. Nephrostomy tract dilation using a balloon dilator in percutaneous renal surgery: Experience with 95 cases and comparison with the fascial dilator system. Urol Int. 2003;71(4):382-4. https://doi.org/10.1159/000074090 PMid:14646437

21. Stoller ML, Wolf JS Jr., St Lezin MA. Estimated blood loss and transfusion rates associated with percutaneous nephrolithotomy. J Urol. 1994;152(6-1):1977-85. https://doi.org/10.1016/ s0022-5347(17)32283-8

PMid:7966654

22. Kukreja R, Desai M, Patel S, Bapat S, Desai M. Factors affecting blood loss during percutaneous nephrolithotomy: Prospective study. J Endourol. 2004;18(8):715-22. https://doi. org/10.1089/0892779042360599

PMid:15659890

23. Kurtulus FO, Fazlioglu A, Tandogdu Z, Aydin M, Karaca S, Cek M. Percutaneous nephrolithotomy: Primary patients versus patients with history of open renal surgery. J Endourol. 2008;22(12):2671-6. https://doi.org/10.1089/end.2007.0431 PMid:19099516

24. Gupta N, Mishra S, Nayyar R, Seth A, Anand A. Comparative analysis of percutaneous nephrolithotomy in patients with and without a history of open stone surgery: Single center experience. J Endourol. 2009;23(6):913-6. https://doi. org/10.1089/end.2008.0660

PMid:19496724

25. Falahatkar S, Panahandeh Z, Ashoori E, Akbarpour M, Khaki N. What is the difference between percutaneous nephrolithotomy in patients with and without previous open renal surgery? $\mathrm{J}$ Endourol. 2009;23(7):1107-10. https://doi.org/10.1089/ end.2008.0630

PMid:19530947

26. Singh I, Kumar A, Kumar P. "Ambulatory PCNL" (tubeless PCNL under regional anesthesia)-a preliminary report of 10 cases. Int Urol Nephrol. 2005;37(1):35-7. https://doi.org/10.1007/ s11255-004-6706-9

PMid:16132756

27. Shahrour W, Andonian S. Ambulatory percutaneous nephrolithotomy: Initial series. Urology. 2010;76(6):1288-92. https://doi.org/10.1016/j.urology.2010.08.001

28. Albala DM, Assimos DG, Clayman RV, Denstedt JD, Grasso M, Gutierrez-Aceves J, et al. Lower pole I: A prospective randomized trial of extracorporeal shock wave lithotripsy and percutaneous nephrostolithotomy for lower pole nephrolithiasis-initial results. J Urol. 2001;166(6):2072-80. https://doi.org/10.1016/ s0022-5347(05)65508-5

PMid:11696709

29. Giusti G, Piccinelli A, Maugeri O, Benetti A, Taverna G, Graziotti P. Percutaneous nephrolithotomy: Tubeless or not tubeless? Urol Res. 2009;37(3):153-8. https://doi.org/10.1007/ s00240-009-0183-7

PMid:19326109

30. Shoma AM, Elshal AM. Nephrostomy tube placement after percutaneous nephrolithotomy: Critical evaluation through a prospective randomized study. Urology. 2012;79(4):771-6. https://doi.org/10.1016/j.urology.2011.09.042

PMid:22130359

31. Bayar G, Kadihasanoglu M, Aydin M, Sariogullari U, Tanriverdi O, Kendirici M. The effect of stone localization on the success and complication rates of percutaneous nephrolithotomy. Urol J. 2014;11(6):1938-42.

PMid:25433471

32. Wiesenthal JD, Ghiculete D, D'A Honey RJ, Pace KT. A comparison of treatment modalities for renal stones between 100 and $300 \mathrm{~mm}^{2}$ : Are shockwave lithotripsy, ureteroscopy, and percutaneous nephrolithotomy equivalent? J Endourol. 2011;25(3):481. https://doi.org/10.1089/end.2010.0208 PMid:21351888

33. Netto NR Jr., Ikonomidis J, Ikari O, Claro JA. Comparative study of percutaneous access for staghorn stones. Urology. 2005;65(4):659-63. https://doi.org/10.1016/j.urology.2004.10.081 PMid:15833502

34. Tefekli A, Ali Karadag M, Tepeler K, Sari E, Berberoglu Y, Baykal M, et al. Classification of percutaneous nephrolithotomy complications using the modified clavien grading system: Looking for a standard. Eur Urol. 2008;53(1):184-90. https://doi. org/10.1016/j.eururo.2007.06.049 PMid:17651892

35. Troxel SA, Low RK. Renal intrapelvic pressure during percutaneous nephrolithotomy and its correlation with the development of postoperative fever. J Urol. 2002;168(4-1):134851. https://doi.org/10.1016/s0022-5347(05)64446-1 PMid:12352390

36. Shaban A, Kodera A, Elghoneimy MN, Orban T, Mursi K, Hegazy A. Safety and efficacy of supracostal access in percutaneous renal surgery. J Endourol. 2008;22(1):29-34. https://doi.org/10.1089/end.2007.0054

PMid:18095859 